Annales Geophysicae (2002) 20: 501-509 (C) European Geophysical Society 2002



\title{
A case study of HF radar spectral width in the post midnight magnetic local time sector and its relationship to the polar cap boundary
}

\author{
E. E. Woodfield ${ }^{1}$, J. A. Davies ${ }^{1}$, P. Eglitis ${ }^{2}$, and M. Lester ${ }^{1}$ \\ ${ }^{1}$ Department of Physics and Astronomy, University of Leicester, Leicester, LE17RH, UK \\ ${ }^{2}$ Swedish Institute of Space Physics, Uppsala Division, Box 537, S-751 21 Uppsala, Sweden, and The Finnish Meteorological \\ Institute, P. O. Box 503, Fin-00101 Helsinki, Finland
}

Received: 29 May 2001 - Revised: 24 October 2001 - Accepted: 31 October 2001

\begin{abstract}
The aim of this paper is to advance the current understanding of the spectral width parameter observed by coherent high frequency (HF) radars. In particular, we address the relationship of a frequently observed gradient, between low $(<200 \mathrm{~m} / \mathrm{s})$ and high $(>200 \mathrm{~m} / \mathrm{s})$ spectral width, to magnetospheric boundaries. Previous work has linked this gradient in the spectral width, in the nightside sector of magnetic local time, to the Polar Cap Boundary (PCB), and also to the boundary between the Central Plasma Sheet (CPS) and the Plasma Sheet Boundary Layer (PSBL). The present case study investigates the former by comparison with the $630.0 \mathrm{~nm}$ optical emission. No suitable data were available to test the second of the two hypotheses. It is found that during the interval in question the spectral width gradient is within the region of the $630.0 \mathrm{~nm}$ optical emission. A comparison of coherent and incoherent scatter radar data is also conducted, which indicates that values of high spectral width are typically collocated with elevated F-region electron temperatures. We conclude that the high spectral width region in the interval under study is associated with particle precipitation and also that the spectral width gradient is not a reliable method for locating the PCB.
\end{abstract}

Key words. Ionosphere (auroral ionosphere; ionospheric irregularities)

\section{Introduction}

The magnetosphere is dynamic and the locations of different plasma regimes within it evolve continually. The boundaries between the different regimes can move, for example, in response to coupling between the interplanetary magnetic field (IMF) and the geomagnetic field, and magnetospheric substorms. In order to study the dynamical processes in the magnetosphere it is necessary to follow the dynamics of the plasma regimes. Many of the processes that occur in the

Correspondence to: E. E. Woodfield

(Emma.Woodfield@ion.le.ac.uk) magnetosphere leave signatures in the ionosphere that can be observed either from the ground or from space. Detecting and tracking the ionospheric signatures of magnetospheric processes is a task ideally suited to ground-based instruments because of their large spatial and temporal coverage.

Of particular interest in the magnetosphere is the open/closed field line boundary (OCFLB). At ionospheric altitudes this is often referred to as the polar cap boundary (PCB), the polar cap being the region in the ionosphere that maps to open field lines in the magnetosphere. Several ionospheric proxies have been suggested for locating the PCB (e.g. Blanchard et al., 1995; Doe et al., 1997; Rodger, 2000). Blanchard and co-workers used DMSP satellite data to show that a well-defined step in the intensity of the $630.0 \mathrm{~nm}$ emission at its poleward edge locates the PCB to an accuracy of $\pm 0.9^{\circ}$ invariant latitude in the pre-midnight sector. This step indicates the change from high-energy precipitation on closed field lines to the low energy, diffuse polar rain observed within the polar cap itself.

Recent work has suggested that a marked gradient between areas of high $(>200 \mathrm{~m} / \mathrm{s})$ and variable, and low $(<200 \mathrm{~m} / \mathrm{s})$ Doppler spectral width values measured by HF radars can also be used as a proxy for the PCB on the nightside, since in the case presented by Lester et al. (2001), it follows the poleward edge of the $630.0 \mathrm{~nm}$ emission in the pre-midnight sector. This spectral width gradient occurs frequently in radar data both on the day and nightside (Baker et al., 1995; Dudeney et al., 1998; André et al., 1999). On the dayside, the region of high spectral width poleward of the spectral width gradient is a well-known signature of the cusp (e.g. Baker et al., 1995; André et al., 1999; Milan et al., 1999). On the nightside, in addition to the PCB, the spectral width gradient has been linked to the magnetospheric boundary between the central plasma sheet (CPS) and plasma sheet boundary layer (PSBL) (Lewis et al., 1997; Dudeney et al., 1998). This boundary is located between two regions of closed field line plasma and will, therefore, map into the ionosphere equatorward of the PCB.

Several physical explanations for the creation of these re- 
gions of high spectral width have been suggested. Simulation runs through standard HF coherent radar analysis software have shown that high spectral width values can be generated by broadband wave activity in the Pc1/Pc2 frequency band (André et al., 1999, 2000a). The presence of suitable waves has been verified by satellite measurements of the cusp that show a step-like increase of wave activity in the frequency band $0.2-2.2 \mathrm{~Hz}$ with electric field measurements of a few $\mathrm{mV} / \mathrm{m}$, coincident with cusp particles (e.g. Maynard et al., 1991; Matsuoka et al., 1993). On the nightside, electrostatic wave activity of a similar frequency range (assumed to be driven by electron precipitation) increases across the CPS/PSBL boundary (Dudeney et al., 1998). Work by Schiffler et al. (1997) and followed up by Huber and Sofko (2000) has found SuperDARN double-peak spectra in the region of the low-latitude boundary layer (LLBL). These would naturally lead to high spectral widths. They attribute the generation of these double-peak spectra to small-scale vortices $(<26 \mathrm{~km}$ and $<4 \mathrm{~s}$ lifetime) which are smaller than the normal spatial and temporal resolution of the SuperDARN radars. They suggest that these vortices may be formed in one of two ways. Ion precipitation spreads radially through charge exhange collisions as it travels downwards in the ionosphere (Davidson, 1965). Thus, if it is co-located with electron precipitation (which does not suffer the same effect), a radial electric field will be produced and hence, a vortex will be the result. Alternatively, vortices may form as a result of the Kelvin-Helmholtz instability to be found at velocity shears, which, when located within a range cell, would themselves be expected to produce a spectrum with more than one peak (André et al., 2000b). André et al. (2000b) also modelled the effect of a small vortex on the standard SuperDARN fitting software and concluded that a vortex smaller than $5 \mathrm{~km}$ would not generate a clear multi-component spectrum in the radar data.

In this case study from 20 December 1998, one of the CUTLASS (Co-operative UK Twin Located Auroral Sounding System) coherent HF radars, part of the SuperDARN network (Greenwald et al., 1995), is used to show that a gradient between low and high variable spectral width is not necessarily a good proxy for the open/closed field line boundary on the nightside. We also demonstrate that elevated electron temperatures caused by particle precipitation in the F-region may be related to the region of high variable spectral width during this period.

\section{Experimental overview}

The CUTLASS pair is the eastern most pair of the SuperDARN network (Greenwald et al., 1995). The two CUTLASS radars are located at Pykkvibær, Iceland $\left(64.5^{\circ} \mathrm{N}\right.$, $68.5^{\circ} \mathrm{E}$ geomagnetic-altitude adjusted corrected geomagnetic (AACGM) coordinates based on Baker and Wing (1989) will be employed hereafter) and at Hankasalmi, Finland $\left(58.6^{\circ} \mathrm{N}, 104.9^{\circ} \mathrm{E}\right)$. Both radars scan through $16 \mathrm{az}-$ imuthal beams arranged symmetrically about the radar bore



Fig. 1. Map indicating the location of the fields-of-view of the instruments used in this study. Only the IMAGE magnetometer stations referred to in the text are plotted.

site. In the standard operating mode the dwell time on each beam is typically $7 \mathrm{~s}$ and the scan starts every two minutes in standard common mode operation. Each beam is separated into 75 range gates. In standard common mode these range gates are $45 \mathrm{~km}$ in length with a distance to the first gate of $180 \mathrm{~km}$. The radars can operate at frequencies between 8 and $20 \mathrm{Mhz}$. The fields-of-view of the two radars overlap to facilitate bistatic velocity measurements.

The radar field-of-view covers some $4 \times 10^{6} \mathrm{~km}^{2}$, although often only a proportion of this area produces ionospheric backscatter. There are two reasons for this, the first being that HF radio propagation in the ionosphere does not uniformly illuminate the region. Secondly, if there are no field-aligned irregularities, then there will be no targets to scatter from and hence, no backscatter. Therefore, care is required in deducing geophysical data from boundaries of backscatter, since the edge may be due to the end of the region illuminated by the radar and not the edge of the location of field-aligned irregularities. However, in this interval, the boundary in question is in the middle of a region of powerful backscatter from similar elevation angles and can, therefore, be assumed to be due to a change in the physical characteristics of the irregularities being observed.

In this study we only use Finland radar data, and the fieldof-view from Hankasalmi is shown in Fig. 1. The radar was performing $7 \mathrm{~s}$ dwell time scans on each beam with standard common mode range gates, although the beam direction re- 
verted to beam 5 after each other beam to give a higher time resolution for beam 5 until 05:00 UT when the scan resumed its normal consecutive order. The time resolution for beam 9 from 01:00 UT to 05:00 UT was 224 $\mathrm{s}$ and from 05:00 UT to 06:00 UT it was $120 \mathrm{~s}$. During the dwell time, when sounding in a particular beam direction, the radar transmits a 7pulse sequence repetitively (approximately 10 multi-pulse sequences can be transmitted each second). Samples of the returned signal are taken, correlated and integrated, so as to give the auto-correlation function of the scattered signal for each range gate. As described more fully by Villain et al. (1987), the signal power, the rate of change of phase angle and the rate of decay of the auto-correlation function are parameterized, leading to an estimate of backscatter power, line-of-sight velocity and spectral width, respectively, of the particular scattering targets occupying each radar range gate. The spectral width is the particular parameter of interest in this paper. It is strictly a measure of the correlation time of the radar signal. For example, the scattering properties of the ground remain fairly uniform with time and hence, the spectral width of ground scatter is typically small. For ionospheric scatter the coherence in the signal and hence, the spectral width is normally related to the variation in the plasma flow in the radar scatter volume. In this paper, we concentrate on identifying specific regions of radar scatter that have a characteristic spectral width.

Observations from two of the European Incoherent SCATter (EISCAT) radars have also been included in this work (Rishbeth and Williams, 1985). The VHF radar at Troms $\varnothing$ $\left(66.4^{\circ} \mathrm{N}, 103.5^{\circ} \mathrm{E}\right)$ and the UHF EISCAT Svalbard Radar (ESR) $\left(75.0^{\circ} \mathrm{N}, 113.0^{\circ} \mathrm{E}\right)$, (Wannberg et al., 1997) provide estimates of a variety of plasma parameters including electron temperature and ion velocity. The VHF radar at Troms $\varnothing$ was operating in split beam mode for the majority of the interval 01:00 to 06:00 UT on 20 December 1998; the two poleward pointing beams are shown in Fig. 1. Beam one has an azimuth of $345.0^{\circ}$ clockwise to geographic north and beam two has an azimuth of $359.5^{\circ}$. Also shown is the equatorward pointing ESR beam which has an azimuth of 161.6 . All three beams were at an elevation of $30.0^{\circ}$. Only data from the modes of operation described above are included in this investigation.

Optical observations from the meridian scanning photometer (MSP) at Longyearbyen on Svalbard $\left(75.0^{\circ} \mathrm{N}\right.$, $\left.113.0^{\circ} \mathrm{E}, \mathrm{AACGM}\right)$ are employed. The MSP observes at four different wavelengths, $427.8 \mathrm{~nm}, 486.1 \mathrm{~nm}, 557.7 \mathrm{~nm}$ and $630.0 \mathrm{~nm}$. Only the $557.7 \mathrm{~nm}$ (green line) and $630.0 \mathrm{~nm}$ (red line) emissions are utilised in this study. The photometer scans from an elevation of $0^{\circ}$, at an azimuth of $45^{\circ}$, to $0^{\circ}$ elevation at an azimuth of $225^{\circ}$. Each scan takes two seconds and repeats every $16 \mathrm{~s}$.

Observations from the IMAGE network of magnetometers (Viljanen and Hakkinen, 1997) supply information about ionospheric currents during the interval. The locations of the IMAGE stations employed in this paper are also plotted in Fig. 1.

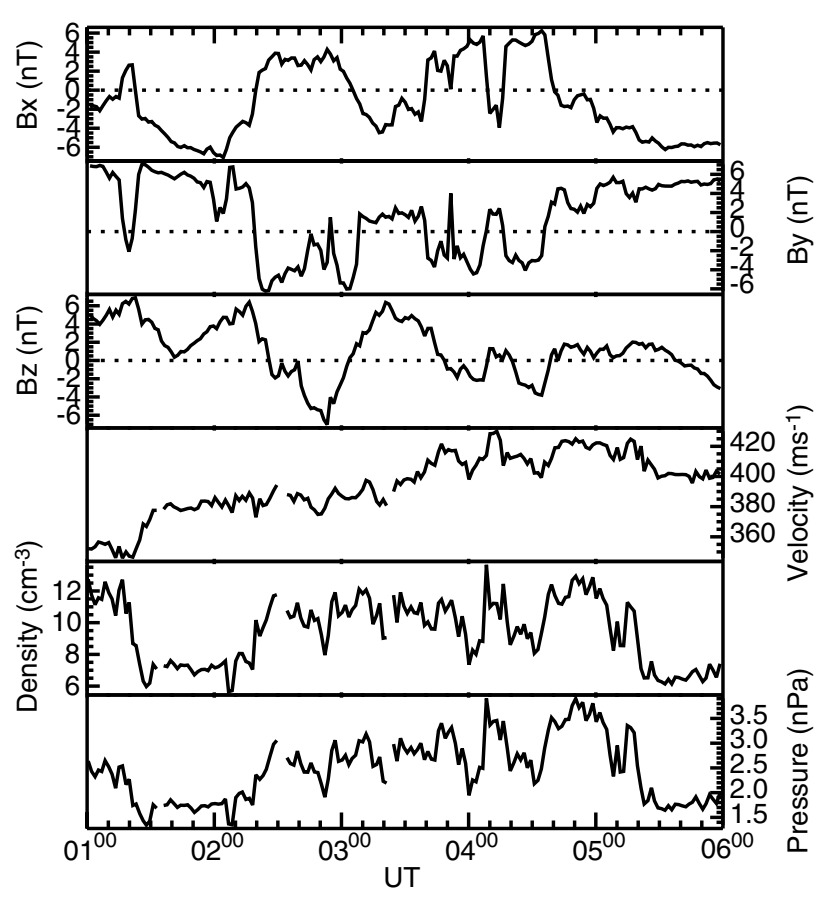

Fig. 2. Solar wind and IMF data from the WIND SWE and MFI instruments on 20 December 1998. The times shown are at the spacecraft, a time delay of $\sim 10$ min to the ionosphere has been calculated. The top three panels display components of the interplanetary magnetic field in GSM coordinates. The bottom three panels indicate solar wind bulk velocity, density and pressure, respectively. WIND was located at approximately $\left(40 R_{E}, 60 R_{E}\right.$, $\left.10 R_{E}\right),(X, Y, Z)$ in GSM coordinates during this interval.

\section{Observations}

\subsection{Interplanetary conditions}

The interval under investigation takes place on the morning of 20 December 1998, from 01:00 UT to 06:00 UT. The IMF and solar wind data taken by the MFI (Lepping et al., 1995) and SWE (Ogilivie et al., 1995) instruments on the WIND spacecraft are shown in Fig. 2. The spacecraft was located at $\left(40 R_{E}, 60 R_{E}, 10 R_{E}\right),(X, Y, Z)$ in GSM coordinates from which point a time delay of $\sim 10 \mathrm{~min}$ from the satellite to the magnetopause has been estimated. This time delay has not been added to any of the times referred to for the spacecraft. The $z$ component of the interplanetary magnetic field $\left(B_{z}\right)$ is northwards at the spacecraft from 00:30 UT until 02:25 UT, when it becomes weakly southward at first and then more strongly southward after 02:50 UT. At 03:00 UT, $B_{z}$ then returns northward until 03:40 UT when it becomes variable until 05:35 UT, after which it becomes increasingly southward. The $y$ component $\left(B_{y}\right)$ is positive until a sudden, large jump from $+6 \mathrm{nT}$ to $-6 \mathrm{nT}$ at $02: 20 \mathrm{UT}$. It is variable after this until another extended period of positive values begins at 04:35 UT. The $x$ component $B_{x}$ is approximately in antiphase with $B_{y}$ throughout the interval.

The solar wind velocity at the spacecraft increases from 




Fig. 3. HF radar data from CUTLASS Finland beam 9, 20 December 1998, (a) Doppler spectral width, (b) line-of-sight velocity (blue is towards the radar), (c) backscatter power. MSP data from Longyearbyen, (d) $630.0 \mathrm{~nm}$, red emission, from an assumed altitude of $250 \mathrm{~km}$, (e) $557.7 \mathrm{~nm}$, green emission, from an assumed altitude of $110 \mathrm{~km}$. All 5 panels have the spectral width gradient at $200 \mathrm{~m} / \mathrm{s}$ overlaid on them in white for comparison. The intervals marked "G.S" have been identified as ground scatter.

$\sim 350 \mathrm{~km} / \mathrm{s}$ at 00:00 UT to $\sim 420 \mathrm{~km} / \mathrm{s}$ at 03:30 UT, after which it decreases to $\sim 400 \mathrm{~km} / \mathrm{s}$. The density and pressure values indicate a trough between 01:20 UT and 02:20 UT with the density decreasing sharply from $12 \mathrm{~cm}^{-3}$ to $7 \mathrm{~cm}^{-3}$. At 02:20 UT, the density and pressure recover quickly to their previous levels where they remain until 05:20 UT when another sharp decrease is observed.

\subsection{CUTLASS data}

The Doppler spectral width, line-of-sight irregularity drift velocity and backscatter power from beam 9 of the Finland radar from 01:00 UT to 06:00 UT on 20 December 1998, are shown in panels (a) to (c) of Fig. 3 (positive velocities are directed towards the radar). To convert UT to magnetic local time (MLT) in the region of magnetic latitude covered by the CUTLASS Finland field-of-view, add approximately $2.5 \mathrm{~h}$ to the UT. F-region backscatter is observed from 02:00 to $05: 00 \mathrm{UT}$ northward of $65^{\circ} \mathrm{N}$ during this time. The scatter shown between 01:00 UT and 01:30 UT, and also from 05:45 UT to 06:00 UT, has been identified as ground scatter

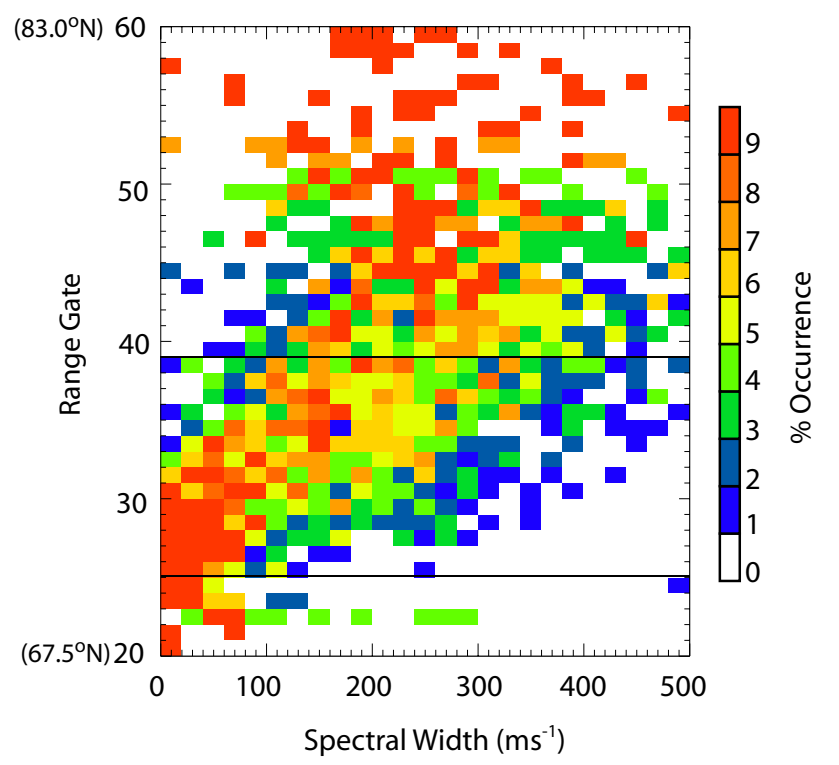

Fig. 4. A contour plot of spectral width distributions for beam 9 , range gates $20\left(\sim 67.5^{\circ} \mathrm{N}\right)$ through $60\left(\sim 83.0^{\circ} \mathrm{N}\right)$ for the interval 01:30 UT to 05:30 UT. The colour scale indicates percentage occurrence with the distributions normalised to the total number of observations from each range gate. The very low spectral width values are not due to ground scatter.

using elevation angle data. The SuperDARN radars typically identify data with spectral widths below $20 \mathrm{~m} / \mathrm{s}$ and velocity magnitude below $50 \mathrm{~m} / \mathrm{s}$ as arising due to ground scatter. In general, this approach is highly effective. However, for the particular F-region scatter interval between 01:30 UT and 05:30 UT of interest here, the standard method led to the misidentification of some of the ionospheric scatter between $68^{\circ} \mathrm{N}$ and $75^{\circ} \mathrm{N}$ as ground scatter. Consequently all ground scatter was identified by studying the elevation angle data. The F-region backscatter power, panel (c) of Fig. 3, is consistently high throughout the interval 02:00 UT to 05:00 UT. The position of the poleward edge of the F-region backscatter varies between $73^{\circ}$ and $84^{\circ}$, while the equatorward edge remains fairly static between $67^{\circ}$ and $69^{\circ}$.

In the Doppler spectral width data, Fig. 3a, there is an area of low spectral width $(<200 \mathrm{~m} / \mathrm{s})$ equatorward of a large area of high $(>200 \mathrm{~m} / \mathrm{s})$ but variable spectral width. A typically sharp nightside gradient in width, $\sim 60 \pm 30 \mathrm{~m} / \mathrm{s} /$ degree, exists between these two regions and is shown by the white line in Fig. 3a. This boundary has been overlaid on all the other panels of Fig. 3 for comparison. A plot of the spectral width distributions for each range gate from 20 to 60, covering a latitude range from $67.5^{\circ} \mathrm{N}$ to $83.0^{\circ} \mathrm{N}$, is shown in Fig. 4. A bin width of $20 \mathrm{~m} / \mathrm{s}$ has been used. The data are taken from the interval of F-region scatter from 01:30 UT to 05:30 UT and have been normalized to the total number of observations in each range gate. The very low spectral widths are not a result of ground scatter since the time interval and range gates chosen contain only F-region scatter. There is an obvious change from distributions peaked between 0 to $20 \mathrm{~m} / \mathrm{s}$ 


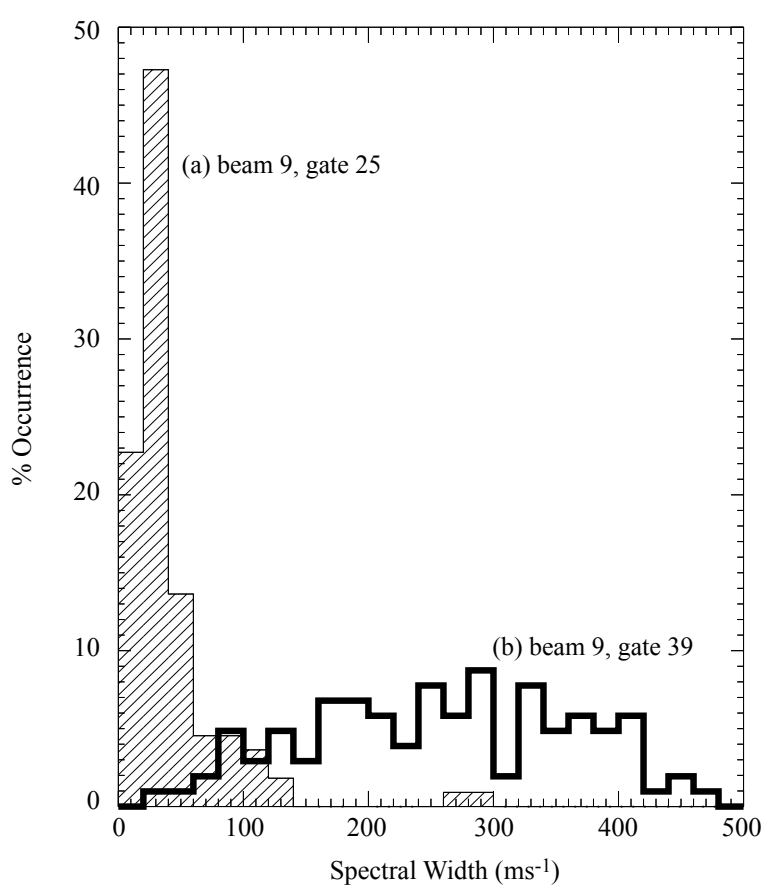

Fig. 5. Two histograms displaying spectral width distributions for (a) beam 9 , range gate $25\left(\sim 69.6^{\circ} \mathrm{N}\right)$, and (b) beam 9 , range gate $39\left(\sim 75.3^{\circ} \mathrm{N}\right)$. Each histogram is normalized to the total number of observations from that gate.

up to range gate $30\left(\sim 71^{\circ} \mathrm{N}\right)$, to those distributions where the peak is around $250 \mathrm{~m} / \mathrm{s}$ above range gate $40\left(\sim 75^{\circ} \mathrm{N}\right)$. In between $71^{\circ} \mathrm{N}$ and $76^{\circ} \mathrm{N}$, a transition between these two extremes is observed; this corresponds to the latitude region within which the $200 \mathrm{~m} / \mathrm{s}$ gradient moves during this interval. Figure 5 presents the distributions of the spectral width for range gates $25\left(\sim 69.9^{\circ} \mathrm{N}\right)$ and $39\left(\sim 75.3^{\circ} \mathrm{N}\right)$ of Finland beam 9 for the interval 01:30 UT to 05:30 UT; the black lines on Fig. 4 show their location. It is clear that the more northerly range gate 39 shows a much more rounded distribution, with a significant percentage $(\sim 66 \%)$ of spectral width values larger than $200 \mathrm{~m} / \mathrm{s}$, while range gate 25 has virtually no data points above $100 \mathrm{~m} / \mathrm{s}$. Therefore, we feel justified in using a value of $200 \mathrm{~m} / \mathrm{s}$ when locating the spectral width gradient in the time series plots of Fig. 3. The form of the rounded distribution for gate 39 resembles closely that of the spectral width distribution identified by Baker et al. (1995), as being a proxy for the location of the cusp on the dayside.

The line-of-sight velocity data (Fig. 3b) indicates that the highest velocities are at the poleward edge of the F-region backscatter, and that these velocities have a component that is directed towards the radar (in blue). The strong bursts of flow with components towards the radar that occur at 03:10 UT and 03:50 UT are associated with pronounced velocity enhancements in anti-sunward flow. There is evidence of long period wave activity (ULF) in the line-of-sight velocity data, from 02:10 UT to 04:00 UT between $69^{\circ}$ and $74^{\circ}$. The period of the wave is approximately $10 \mathrm{~min}$. We return to this observation in Sect. 3.4.

\subsection{Meridian scanning photometer data}

The optical data for two wavelengths, $630.0 \mathrm{~nm}$ and $557.7 \mathrm{~nm}$, taken from the Longyearbyen MSP for the interval 01:00 UT to 06:00 UT on 20 December 1998 are shown in Fig. 3d and 3e, respectively. These have been plotted as a function of magnetic latitude, assuming an altitude of $250 \mathrm{~km}$ for the emission at $630.0 \mathrm{~nm}$ and $110 \mathrm{~km}$ for $557.7 \mathrm{~nm}$. The assumed altitudes are seen to be reasonable in the discussion.

There is structure in both the $630.0 \mathrm{~nm}$ and $557.7 \mathrm{~nm}$ emissions from 01:00 UT until 01:40 UT when a sudden decrease to very low intensity emission occurs. This lack of emission lasts until 02:40UT. Coincidentally, the time-span of this marked drop in intensity is the same as the density decrease observed by WIND when a time lag of $20 \mathrm{~min}$ from the spacecraft is included. It may be possible that the two events are related in some way, with the additional delay of $10 \mathrm{~min}$ a result of the reaction time in the nightside ionosphere to the change at the magnetopause. The optical intensity decrease between 01:40 UT and 02:40 UT hails the beginning of the region of ionospheric scatter observed by the Finland $\mathrm{HF}$ radar. The region of ionospheric scatter expands quickly to cover latitudes from $67^{\circ} \mathrm{N}$ up to $83^{\circ} \mathrm{N}$, then the poleward edge of it contracts dramatically just before 02:40 UT to $76^{\circ} \mathrm{N}$. The $630.0 \mathrm{~nm}$ emission then takes the form of a narrow band of high intensity, i.e. above $3 \mathrm{kR}$, which is approximately $2^{\circ}$ wide in latitude at 02:40 UT. The peak intensity of the main emission moves equatorwards from $75^{\circ} \mathrm{N}$ to $71^{\circ} \mathrm{N}$, during the interval 02:40 UT to 04:20 UT. After this, the peak emission moves polewards to $77^{\circ} \mathrm{N}$, once again becoming narrow, reaching its maximum latitude at 05:40 UT. Above the main latitude of emission there are several equatorward moving features starting at 03:10 UT, 03:45 UT, 03:55 UT and 04:00 UT. The first and last of these moves from $76^{\circ} \mathrm{N}$ to $73^{\circ} \mathrm{N}$, while the intermediate features move from $75^{\circ} \mathrm{N}$ to $73^{\circ} \mathrm{N}$. The approximate rate of motion is $0.1^{\circ} \pm 0.05^{\circ}$ per minute $(\sim 170 \mathrm{~m} / \mathrm{s})$.

The $557.7 \mathrm{~nm}$ emission, although active simultaneously with the $630.0 \mathrm{~nm}$ emission, has a constant poleward edge at $73^{\circ}$ with a broader region of high intensity, above $3 \mathrm{kR}$, and variable structure equatorward of this latitude. The same reduction in luminosity between 01:40 UT and 02:40 UT is observed in the $557.7 \mathrm{~nm}$ emission, as are the same equatorward moving features from 03:10 UT to 04:00 UT. The peak of the of the $557.7 \mathrm{~nm}$ emission is located at approximately $72^{\circ} \mathrm{N}$ from 02:40 UT until 04:10 UT, when it moves southwards to $70^{\circ} \mathrm{N}$ at 05:00 UT, as the intensity starts to decrease until it is beyond the interval of interest. The equatorward edge of the emission is south of the field-of-view from 02:50 UT until the end of the interval.

\subsection{Magnetometer data}

A $150 \mathrm{nT}$ negative bay is observed in the $X$-component (north-south) data from Sørøya (SOR, 67.1 ${ }^{\circ} \mathrm{N}, 106.7^{\circ} \mathrm{E}$ ) 


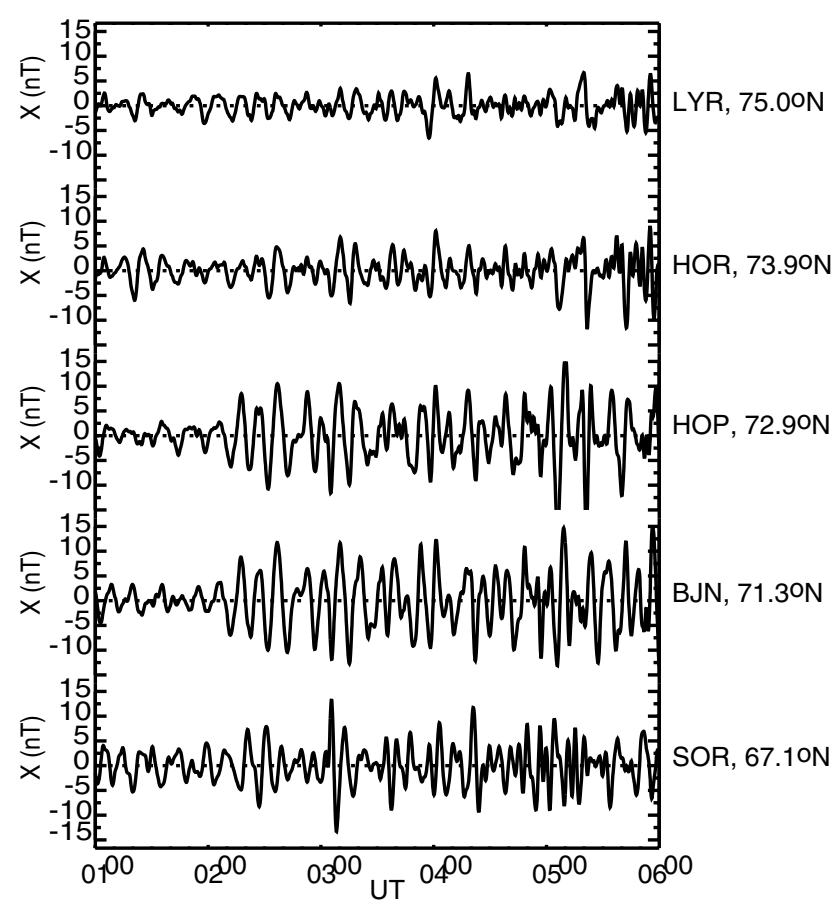

Fig. 6. The north-south component measurements from five of the IMAGE magnetometer stations filtered between $100 \mathrm{~s}$ and $1000 \mathrm{~s}$, 20 December 1998.

to Pello (PEL, $63.3^{\circ} \mathrm{N}, 105.4^{\circ} \mathrm{E}$ ) in the image chain from 00:00 UT to 01:10 UT (not shown). This enhanced westward electrojet decays to previous levels by 01:10 UT and is, therefore, assumed to have no effect on the spectral width boundary indicated in Fig. 3a. Data from five of the magnetometers of the image chain for the period 01:00 UT to 06:00 UT on 20 December 1998 are shown in Fig. 6. The magnetometer data have been band pass filtered using a range of $100 \mathrm{~s}$ to $1000 \mathrm{~s}$. A wave, matching the frequency of the one observed by the Hankasalmi radar $(\sim 2 \mathrm{MHz})$, is recorded by magnetometers of the image chain starting at 02:20 UT. The amplitude of the wave observed by the magnetometers is largest at the stations of Bear Island $\left(\mathrm{BJN}, 71.3^{\circ} \mathrm{N}, 108.9^{\circ} \mathrm{E}\right)$ and Hopen Island $\left(\mathrm{HOP}, 72.9^{\circ} \mathrm{N}, 115.9^{\circ} \mathrm{E}\right)$. There is a sharp decrease in the amplitude of the wave between HOP and Longyearbyen $\left(\mathrm{LYR}, 75.0^{\circ} \mathrm{N}, 113.0^{\circ} \mathrm{E}\right.$ ) and a slower decrease to the south of HOP. Measurements of the latitudinal variation of the amplitude and phase of the wave area are consistent with the wave being a field line resonance (FLR) with the resonating field line poleward of HOP and equatorward of LYR. Since FLRs only occur on closed field lines, a lower limit for the OCFLB can be set at $72.9^{\circ} \mathrm{N}$.

\subsection{Incoherent scatter data}

The first three panels of Fig. 7 show the electron density, electron temperature and ion velocity, respectively, observed by the ESR from 01:00 UT to 06:00 UT. The last two panels of Fig. 7 present the line-of-sight velocity and spectral

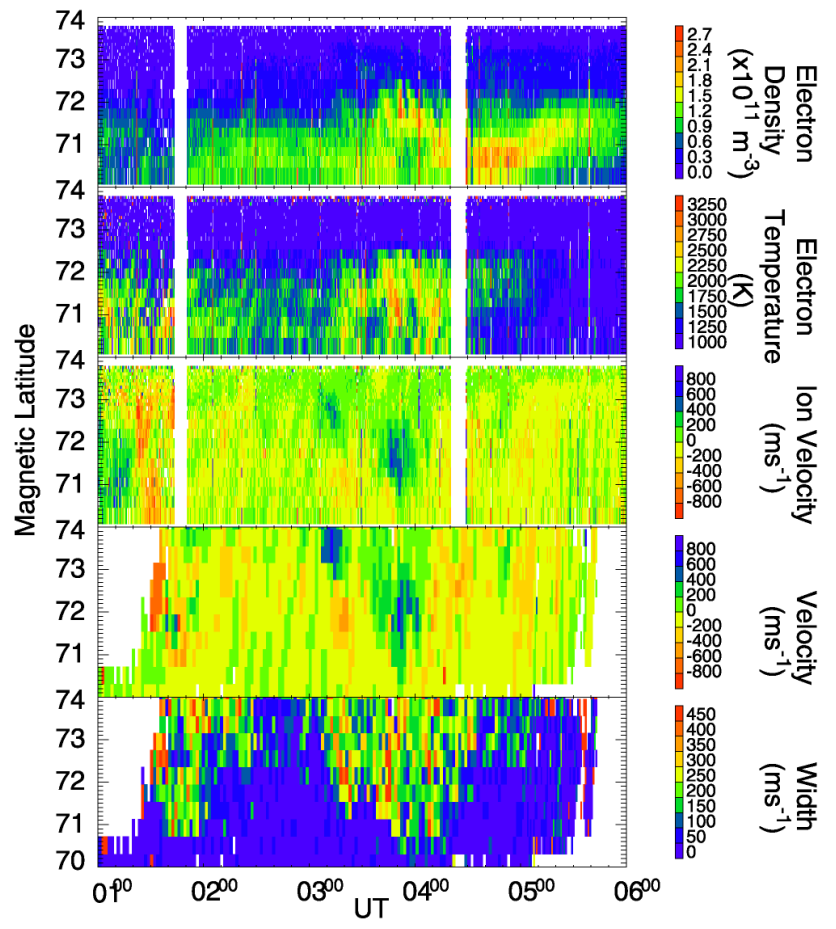

Fig. 7. Data from the EISCAT Svalbard Radar, 20 December 1998, (a) electron density, (b) electron temperature, (c) ion velocity. Data from CUTLASS Finland on a reduced latitude scale from Fig. 3, (d) line-of-sight velocity and (e) spectral width "G.S" denotes intervals of ground scatter.

width from beam 9 of CUTLASS Finland for the same range of magnetic latitudes. The ESR UHF beam was pointing in the same vertical plane as beam 9 of CUTLASS Finland, in the opposite sense during this interval, at an elevation of $30^{\circ}$. The altitude range covered by the data in Fig. 7 is from approximately $90 \mathrm{~km}$ at $74^{\circ} \mathrm{N}$ to $390 \mathrm{~km}$ at $70^{\circ} \mathrm{N}$. Although not shown here, the data from the EISCAT VHF beams show very similar results to those from the ESR. It is evident from Fig. $7 \mathrm{c}$ and $7 \mathrm{~d}$ that the line-of-sight ion velocities from the incoherent radar agree well with the irregularity drift velocities observed by CUTLASS Finland. (Note that all the data shown have positive velocities towards the HF radar at Finland and that the range of magnetic latitudes shown is different from Fig. 3). This is consistent with previous results that the phase speed of F-region irregularities is equal to the component of the ambient plasma flow in their direction of propagation (Davies et al., 2000 and references therein). One can observe the same field line resonance signature as seen from Hankaslami and the same flow bursts at 03:10 UT and 03:50 UT.

Equatorward moving structures are evident in the electron density and electron temperature data, Fig. $7 \mathrm{a}$ and $7 \mathrm{~b}$, respectively, from 03:40 UT to 04:10 UT. These structures are observed by the ESR, while equatorward moving structures are also observed by the MSP, although not simultaneously and at a lower latitude. The equatorward motion is observed at the same time as strong velocity towards Hankaslami, and 


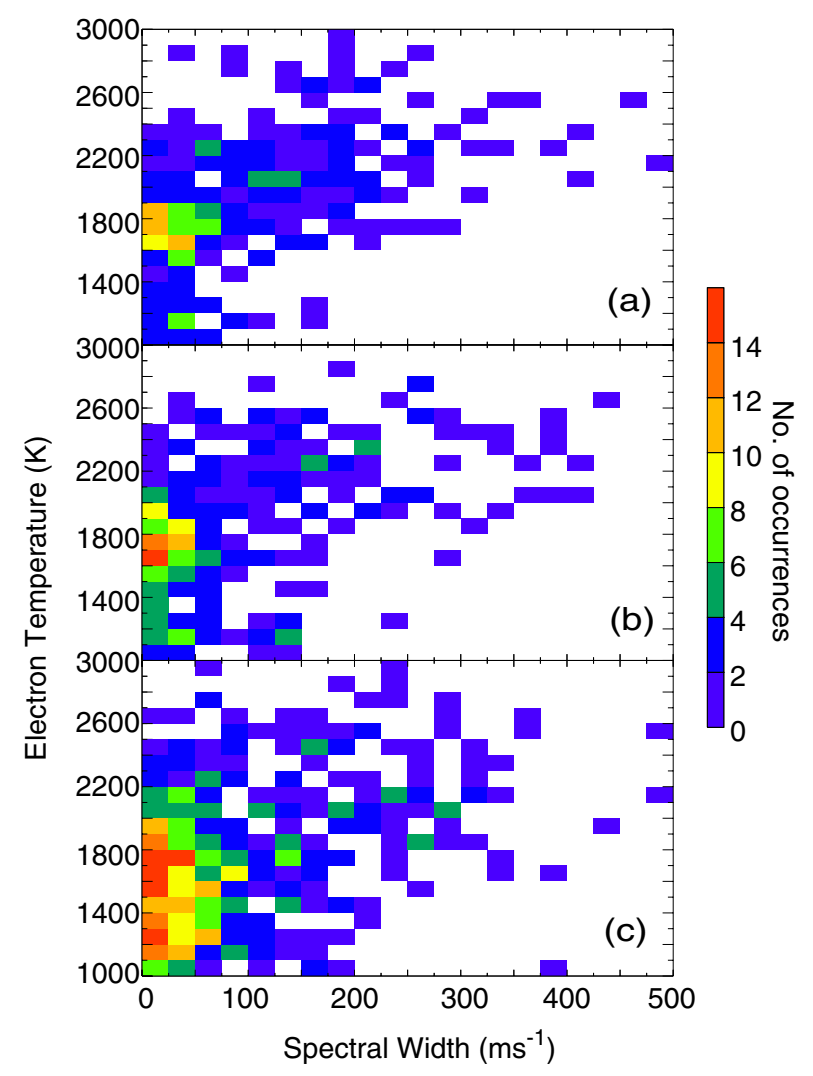

Fig. 8. Scatter plots of electron temperature from the incoherent scatter radar data against spectral width from CUTLASS Finland. The data used has been restricted to between $71^{\circ} \mathrm{N}$ and $72^{\circ} \mathrm{N}$. The colours indicate the frequency of observations within the bin they outline.

also in the latter part of the interval when the spectral width gradient moves equatorward.

The ESR observed two pronounced regions of structured, elevated electron temperature in the F-region, Fig. $7 b$, and this is replicated by the two VHF beams from Troms $\varnothing$, from 01:00 UT and 01:45 UT, and 03:10 UT and 04:20 UT, Fig. 7b. The ESR beam is at F-region altitudes below approximately $73^{\circ} \mathrm{N}$. These regions are clearly seen to be co-located with the areas of high spectral width observed by CUTLASS Finland at these times, Fig. 7e. Figure 8 shows a comparison of the electron temperature from the incoherent scatter radars and spectral width from the Finland radar in the region $71^{\circ} \mathrm{N}$ to $72^{\circ} \mathrm{N}$, which restricts the altitude range of observation to a small slice of the F-region around $300 \mathrm{~km}$. This is done for two reasons: first, to ensure the values are solely from the F-region and second, to avoid any effects due to the underlying increase of electron temperature with altitude found in the topside F-region. Panels (a) to (c) of Fig. 8 show scatter plots of electron temperature from the ESR and beams 1 and 2 of the EISCAT VHF system, respectively, versus colocated and simultaneous HF scatter spectral width. The data have been collected into bins of $50 \mathrm{~m} / \mathrm{s}$ and $100 \mathrm{~K}$, with the colouring indicating the number of observations in each bin.

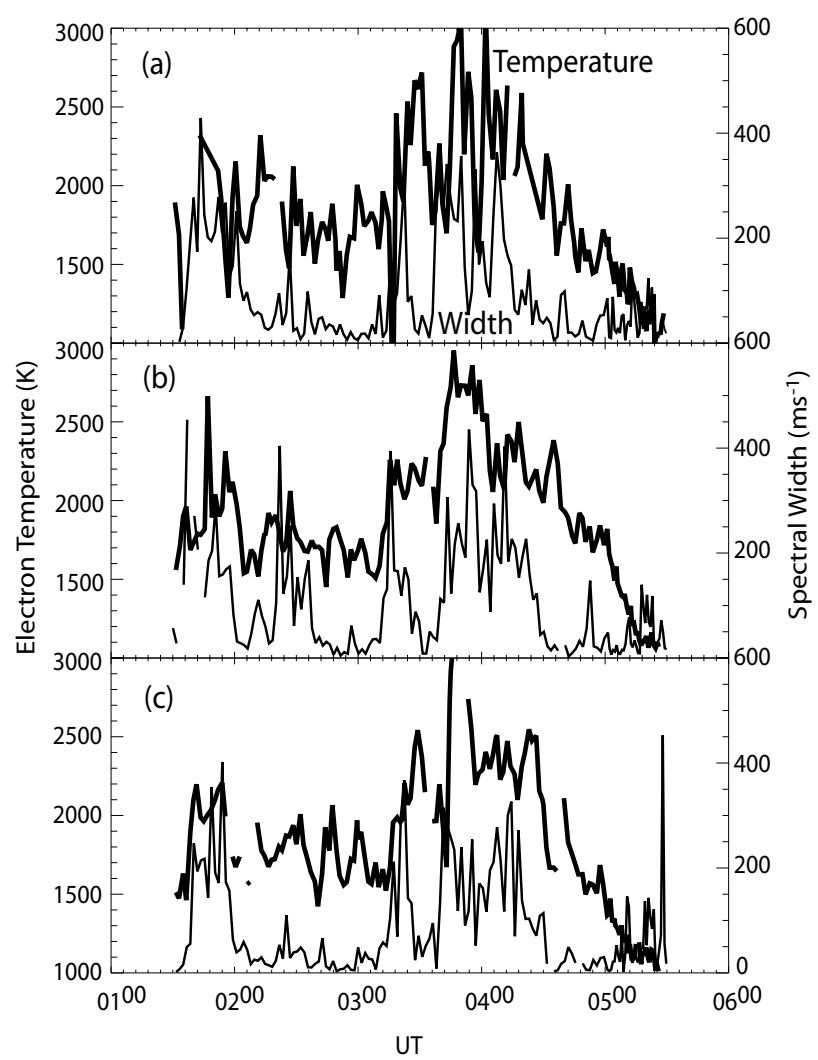

Fig. 9. Line plots comparing co-located and simultaneous measurements of electron temperature from the three incoherent scatter beams and spectral width from beam 9, (a) ESR UHF, (b) EISCAT VHF beam 1, (c) EISCAT VHF beam 2. The locations of these intersecting measurements have been chosen within the range $71^{\circ} \mathrm{N}$ to $72^{\circ} \mathrm{N}$, and at an altitude of $\sim 300 \mathrm{~km}$.

High spectral width values measured by CUTLASS Finland are collocated with elevated electron temperatures although the reverse is not the case. Figure 9 shows a direct comparison of simultaneous, co-located observations for the ESR UHF beam and beams 1 and 2 of the mainland VHF system (a to c, respectively) with the HF radar data. The analysis from both Figs. 8 and 9 shows that although high spectral widths from the HF radar are associated with high electron temperatures, there are also regions of elevated electron temperature associated with very low spectral width. Also, note that the elevated electron temperature feature is spatially extended in longitude as it occurs in all three incoherent scatter radar beams.

\section{Discussion}

A previous case study in the pre-midnight sector (Lester et al., 2001) concluded that the well-defined gradient between low $(<200 \mathrm{~m} / \mathrm{s})$ and high $(>200 \mathrm{~m} / \mathrm{s})$ spectral width can be used, with caution, as an ionospheric proxy for the PCB. This conclusion was based on the fact that the gradient would, at times, follow the poleward edge of the $630.0 \mathrm{~nm}$ optical 
emission, which has been proposed as a proxy for the PCB (Blanchard et al., 1995). Blanchard et al. had established that the poleward edge of the $630.0 \mathrm{~nm}$ emission can be used as the ionospheric footprint of the PCB with an accuracy of $\pm 0.9^{\circ}$ in the pre-midnight sector. Lester and colleagues did note that during dynamic intervals, e.g. a weak substorm, the relationship between the spectral width gradient and the poleward border of the red line emission broke down.

The poleward boundary of the $630.0 \mathrm{~nm}$ emission in this interval is confused by the presence of several equatorward moving arcs poleward of the main region of $630.0 \mathrm{~nm}$ emission, Fig. 3d. However, the spectral width gradient is generally significantly equatorward of both the equatorward moving arcs and the poleward edge of the main region of emission. Notably, the spectral width gradient is equatorward of the intense emissions seen at $75^{\circ} \mathrm{N}$ which are not subject to error resulting from assuming an altitude, since all emission at this latitude is directly overhead. In general, the motion in time of the location of the gradient does not follow either the main poleward boundary, or the equatorward moving arcs. This could be a result of the altitude structure of the optical emission changing with time; nevertheless, the spectral width gradient stays equatorward of the emission at $0^{\circ}$ to the zenith. Thus, we assume that the non-correspondence of the spectral width boundary and poleward edge of the $630.0 \mathrm{~nm}$ emission is not a result of the assumed altitude applied to the observations of the $630.0 \mathrm{~nm}$ emission in order to map it to magnetic latitude. The electrojet activity in the vicinity of Scandinavia seen at 00:00 UT, prior to the interval discussed here, has been assumed to have no long lasting effect that would affect the alignment of the spectral width gradient and poleward edge of the $630.0 \mathrm{~nm}$ emission over Scandinavia. Although the spectral width gradient is, for the most part, equatorward of the poleward edge of the $630.0 \mathrm{~nm}$ emission, the one exception to this, between 04:30 UT and 05:00 UT, is due to an ambiguity in determining the location of the spectral width gradient. The difference between this case study and that of Lester et al. (2001) could be a result of the different types of precipitation in the pre- and post-midnight sectors of MLT, as described by Shue et al. (2001). The observations shown in this paper indicate that much of the high spectral width region is actually located on closed field lines. Hence, we conclude that Lester et al. (2001) were correct in advising caution in using the gradient between high and low spectral width as a proxy for the PCB. Furthermore, we conclude that in the post-midnight sector the gradient between large and small spectral width values is exclusively on closed field lines during this case study.

During this interval we have another means of finding the minimum latitude for the PCB, namely the field line resonance seen in both the IMAGE magnetometer data and the Finland and EISCAT radar line-of-sight velocity data, Fig. 6. These observations set a lower limit for the OCFLB at $72.9^{\circ} \mathrm{N}$, since a FLR is expected to occur only on closed field lines. This lower limit for the OCFLB is poleward of the majority of the spectral width gradient's location, which reaches $71^{\circ} \mathrm{N}$ at its lowest point. This would indicate that if the gradient is related to a magnetospheric boundary, then it is more likely to be an indicator of the boundary between the CPS and PSBL (Lewis et al., 1997; Dudeney et al., 1998) since both of these regions are assumed to be on closed field lines.

The incoherent scatter radar data from the EISCAT facilities show an interesting effect to consider further. A first look at Fig. $7 \mathrm{~b}$ and $7 \mathrm{e}$ seems to indicate a correspondence between regions of elevated electron temperature and high spectral width. Upon further comparison of the F-region electron temperature data from the EISCAT and ESR data with the spectral width values, we find that regions of high spectral width are associated with regions of high electron temperature, but not vice versa. Only data between $71^{\circ} \mathrm{N}$ and $72^{\circ} \mathrm{N}$ are used to eliminate the underlying change in the electron temperature with altitude that is present in the F-region. This latitude range also restricts both CUTLASS, EISCAT and ESR radars to F-region altitudes. If one assumes that elevated electron temperatures are linked to electron precipitation, then there is a relationship here between F-region electron precipitation and high spectral widths in the F-region. Following from this interpretation it is possible that the relationship between elevated electron temperature and high spectral width on closed field lines is a signature of small-scale vortex activity resulting from precipitation. The work of Newell et al. (1996) has characterised the change from structured to unstructured electron precipitation (on a scale of $>5-10 \mathrm{~km}$ ) as boundary "b4s", as observed by DMSP satellites. The decrease in correlation between successive electron spectra above this boundary means that there are spatial stuctures $<5-10 \mathrm{~km}$ at the satellite altitude on closed field lines. These could be the signature of filamentary electron precipitation which could generate small-scales vortices. This case study cannot, however, directly demonstrate this.

\section{Conclusions}

Contrary to a previous case study, the boundary between large and small values of HF radar spectral width for this data set is located exclusively on closed field lines. It follows that the spectral width boundary is not a reliable means of locating the ionospheric footprint of the open/closed field line boundary.

There is, however, evidence for a relationship between high spectral width and elevated electron temperature in the F-region during this interval, leading us to believe that there could be a link between electron precipitation and high spectral width. Further data will be looked at to define this relationship more specifically and determine if low frequency wave activity or small-scale vortices are involved in generating high spectral widths on the nightside.

Acknowledgement. The authors thank R. Smith and V. Besser from University of Alaska, Fairbanks, Alaska, for supplying the MSP data, the institutes who maintain the IMAGE magnetometer array, R. Lepping and K. Ogilivie at NASA/GSFC and CDAWeb for 
WIND data and Rod Mathie formerly at the University of York, UK The CUTLASS HF radars are deployed and operated by the University of Leicester, and are jointly funded by the UK Particle Physics and Astronomy Research Council (PPARC) grant number PPA/R/R/1997/00256, the Swedish Institute for Space Physics, Uppsala and the Finnish Meteorological Institute, Helsinki. EEW is indebted to PPARC for a research studentship. JAD is supported by PPARC grant number PPA/G/O/1999/00181. EISCAT is an international facility funded collaboratively by the research councils of Finland (SA), France (CNRS), the Federal Republic of Germany (MPG), Japan (NIPR), Norway (NAVF), Sweden (NFR) and the UK (PPARC). We thank one of the referees for particularly helpful comments.

The Editor in Chief thanks J. Kelly and G. Sofko for their help in evaluating this paper.

\section{References}

André, R., Pinnock, M., and Rodger, A. S.: On the SuperDARN autocorrelation function observed in the ionospheric cusp, Geophys. Res. Lett., 26, 22, 3353-3356, 1999.

André, R., Pinnock, M., and Rodger, A. S.: Identification of the low-altitude cusp by Super Dual Auroral Radar Network radars: A physical explanation for the empirically derived signature, $\mathrm{J}$. Geophys. Res., 105, 27 081-27 093, 2000a.

André, R., Pinnock, M., Villain, J.-P., and Hanuise, C.: On the factors conditioning the Doppler spectral width determined from SuperDARN HF radars, Int. J. Geomag. Aeronomy., 2, 1, 77-86, 2000b.

Baker, K. B. and Wing, S.: A new magnetic coordinate system for conjugate studies at high-latitudes, J. Geophys. Res., 94, 9139_ 9143, 1989

Baker. K. B., Dudeney, J. R., Greenwald, R. A., Pinnock, M., Newell, P. T., Rodger, A. S., Mattin, N., and Meng, C.-I.: HF radar signatures of the cusp and low-latitude boundary layer, J. Geophys. Res., 100, 7671-7695, 1995.

Blanchard, G. T., Lyons, L. R., Samson, J. C., and Rich, F. J.: Locating the polar cap boundary from observations of $6300 \AA$ auroral emission, J. Geophys. Res., 100, 7855-7862, 1995.

Davidson, G. T.: Expected Spatial Distribution of Low-Energy protons Precipitated in the Auroral Zones, J. Geophys. Res., 70, 1061, 1965.

Davies, J. A., Yeoman, T. K., Lester, M., and Milan, S. E.: A comparison of F-region ion velocity observations from the EISCAT Svalbard and VHF radars with irregularity drift velocity measurements from the CUTLASS Finland HF radar, Ann. Geophysicae, 18, 589-594, 2000.

Doe, R. A., Vickrey, J. F., Weber, E. J., Gallagher, H. A., and Mende, S. B.: Ground-based signatures for the nightside polar cap boundary, J. Geophys. Res., 102, 19 989-20 005, 1997.

Dudeney, J. R., Rodger, A. S., Freeman, M. P., Pickett, J., Scudder, J., Sofko, G., and Lester, M.: The nightside ionospheric response to IMF $B_{y}$ changes, Geophys. Res. Lett., 25, 2601-2604, 1998.

Greenwald, R. A., Baker, K. B., Dudeney, J. R., Pinnock, M., Jones, T. B., Thomas, E. C., Villain, J.-P., Cerisier, J.-C., Senior, C., Hanuise, C., Hunsucker, R. D., Sofko, G., Koehler, J., Nielsen, E., Pallinen, R., Walker, A. D. M., Sato, N., and Yamagishi, H.: DARN/SuperDARN: A global view of the dynamics of the high-latitude convection, Space Sci. Rev., 71, 761-796, 1995.
Huber, M. and Sofko, G. J.: Small-scale vortices in the high-latitude F-region, J. Geophys. Res., 105, 20 885-20 897, 2000.

Lepping, R. P., Acuna, M. H., Burlaga, L. F., Farrell, W. M., Slavin, J. A., Schatter, K. H., Mariani, F., Ness, N. F., Neubauer, F. M., Whang, Y. C., Byrnes, J. B., Kennon, R. S., Panetta, P. V., Scheifele, J., and Worler, E. M.: The WIND magnetic field investigation, Space Sci. Rev., 71, 207-229, 1995.

Lester, M., Milan, S. E., Besser, V., and Smith, R.: A Case Study of HF Radar Spectra and $630.0 \mathrm{~nm}$ Auroral Emission in the Pre Midnight Sector, Ann. Geophysicae, 19, 327-339, 2001

Lewis, R. V., Freeman, M. P., Rodger, A. S., Reeves, G. D., and Milling, D. K.: The electric field response to the growth phase and expansion phase onset of a small isolated substorm, Ann. Geophysicae, 15, 289-299, 1997.

Matsuoka, A., Tsuruda, K., Hayakawa, H., Mukai, T., Nishida, A., Okada, T., Kaya, N., and Fukunishi, H.: Electric field fluctuations and charged particle precipitation in the cusp, J. Geophys. Res., 98, 11 225-11 234, 1993.

Maynard, N. C., Aggson, T. L., Basinka, E. M., Burke, W. J., Craven, P., Peterson, W. K., Suguira, M., and Weimer, D. R.: Magnetospheric boundary dynamics: DE-1 and DE-2 observations near the magnetopause and cusp, J. Geophys. Res., 96, 3505-3522, 1991.

Milan, S. E., Lester, M., Cowley, S. W. H., Moen, J., Sandholt, P. E., and Owen, C. J.: Meridian-scanning photometer, coherent HF radar, and magnetometer observations of the cusp: a case study, Ann. Geophysicae, 17, 159-172, 1999.

Newell, P. T., Feldstein, Y. I., Galperin, T. I., and Meng, C.-I.: Morphology of nightside precipitation, J. Geophys. Res., 101, 10737-10 748, 1996.

Ogilivie, K. W., Chornay, D. J., Fritzenreiter, R. J., Hunsaker, F., Keller, J., Lobell, J., Miller, G., Scudder, J. D., Sittler, Jr., E. C., Torbert, R. B., Bodet, D., Needell, G., Lazarus, A. J., Steinberg, J. T., Tappan, J. H., Mavretic, A., and Gergin, E.: SWE, A comprehensive plasma instrument for the WIND spacecraft, Space Sci. Rev., 71, 55-77, 1995.

Rishbeth, H. and Williams, P. J. S.: The EISCAT Ionospheric Radar: the System and its Early Results, Q. J. R. Astron. Soc., 26, 478$512,1985$.

Rodger, A. S.: Ground-based imaging of Magnetospheric boundaries, Adv. Space Res., 25, 7/8, 1461-1470, 2000.

Schiffler, A., Sofko, G., Newell, P. T., and Greenwald, R.: Mapping the outer LLBL with SuperDARN double-peaked spectra, Geophy. Res. Lett., 24, 3149-3152, 1997.

Shue, J.-H., Newell, P. T., Liou, K., and Meng, C.-I.: The quantitative relationship between auroral brightness and solar EUV Pedersen conductance, J. Geophys. Res., 106, 5583-5894, 2001.

Viljanen, A. and Häkkinen, L.: IMAGE magnetometer network, in: Satellite-Ground Based Coordination Sourcebook, ESA-SP1198, (Eds) Lockwood, M., Wild, M. N., and Opgenoorth, H. J., ESA Publications, ESTEC, Noordwijk, The Netherlands, June, 111-118, 1997.

Villain, J.-P., Greenwald, R. A., Baker, K. B., and Ruohoniemi, J. M.: HF radar observations of E-region plasma irregularities produced by oblique electron streaming, J. Geophys. Res., 92, 12 327-12 342, 1987.

Wannberg, G., Wolf, I., Vanhainen, L.-G., Koskenniemi, K., Röttger, J., Postila, M., Markkanen, J., Jacobsen, R., Stenberg, A., Larsen, R., Eliassen, S., Heck, S., and Hunskonen, A.: The EISCAT Svalbard Radar: A case study in modern incoherent scatter radar system design, Radio. Sci. 32, 6, 2283-2307, 1997. 